\section{Response to: 'Risk of systemic lupus erythematosus in patients with idiopathic thrombocytopenic purpura: population-based cohort study' by
Goulielmos and Zervou}

We thank Goulielmos et $a 1^{1}$ for their interests on our article entitled 'Risk of systemic lupus erythematosus (SLE) in patients with idiopathic thrombocytopenic purpura (ITP): a population-based cohort study'.2

Goulielmos et al raised possible mechanism and explanation about the link of ITP and SLE. We appreciated their review and comments on sensitised platelets, shared genetic background and similar molecular signatures of these two diseases. We also agree that these genetic and molecular background, especially interferon signatures in ITP might lead to development autoimmune diseases, such as SLE.

In this study, we use a big data approach to explore the linkage of ITP and SLE and demonstrated strong association of these two diseases. It is not our purpose to look at the mechanism of this association. We appreciate those creative comments and hypothesis that Goulielmos et al proposed. A recent study also found active role of platelet activation in pathogenesis of SLE. ${ }^{3}$ It definitely need further bench works to prove above hypothesised mechanism.

One possible linkage which Goulielmos et al did not mention is the environmental factors, especially infection. Besides wellknown virus, such as Epstein-Barr virus, cytomegalovirus and parvovirus B19, in our previous studies, we also found that SLE is associated various micro-organisms, including human Papillomavirus, scrub typhus, ${ }^{4}$ Helicobacter pylori, ${ }^{5}$ Mycoplasma pneumonia and non-typhoid Salmonella (data in submission). We think that SLE and other autoimmune diseases all had strong interaction with genetic and environmental factors.

In conclusion, we agree that SLE is a complex disease spectrum with various phenotypes. ITP and certain subtypes of SLE might share molecular and genetic backgrounds. Clinician should recognise ITP might be a subtype of subclinical SLE in managing patients.

Fang Xiao Zhu, ${ }^{1}$ Jing-Yang Huang, ${ }^{2,3}$ James Cheng-Chung Wei $\oplus^{3,4,5}$

'Department of Rheumatology and Immunology, The Second Affiliated Hospital of Guilin Medical University, Guilin, Guangxi, China

2Department of Medical Research, Chung Shan Medical University Hospital,

Taichung, Taiwan

${ }^{3}$ Institute of Medicine, Chung Shan Medical University, Taichung, Taichung, Taiwan
${ }^{4}$ Department of Allergy, Immunology \& Rheumatology, Chung Shan Medical University Hospital, Taichung, Taiwan

${ }^{5}$ Graduate Institute of Integrated Medicine, China Medical University, Taichung, Taiwan

Correspondence to Dr James Cheng-Chung Wei, Institute of Medicine, Chung Shan Medical University, Taichung 40201, Taiwan; jccwei@gmail.com

Handling editor Josef S Smolen

Contributors JCCW: manuscript writing. J-YH: data analysis. FXZ: critical appraisal and approve the manuscript.

Funding Funding The present study was supported by the Programme of Scientific and Technology Project (Guilin Science Research and Technology Development; grant no. 2016012706-2).

Competing interests None declared.

Patient and public involvement Patients and/or the public were not involved in the design, or conduct, or reporting, or dissemination plans of this research.

Patient consent for publication Not required.

Provenance and peer review Commissioned; internally peer reviewed. (c) Author(s) (or their employer(s)) 2020. No commercial re-use. See rights and permissions. Published by BMJ.

\section{Check for updates}

To cite Zhu FX, Huang J-Y, Wei JC-C. Ann Rheum Dis Epub ahead of print: [please include Day Month Year]. doi:10.1136/annrheumdis-2020-218177

Received 24 June 2020

Accepted 25 June 2020

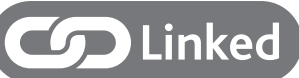

- http://dx.doi.org/10.1136/annrheumdis-2020-218128

Ann Rheum Dis 2020;0:1. doi:10.1136/annrheumdis-2020-218177

ORCID iD

James Cheng-Chung Wei http://orcid.org/0000-0003-0310-2769

\section{REFERENCES}

1 Goulielmos GN, Zervou Ml, et al. Risk of systemic lupus erythematosus inpatients with idiopathic thrombocytopenicpurpura: population-based cohort study. Ann Rheum Dis 2020

2 Zhu F-X, Huang J-Y, Ye Z, et al. Risk of systemic lupus erythematosus in patients with idiopathic thrombocytopenic purpura: a population-based cohort study. Ann Rheum Dis 2020:79:793-9.

3 Andrianova IA, Ponomareva AA, Mordakhanova ER, et al. In systemic lupus erythematosus anti-dsDNA antibodies can promote thrombosis through direct platelet activation. J Autoimmun 2020;107:102355.

4 Chu K-A, Chen W, Hsu CY, et al. Association of scrub typhus with the risk of autoimmune diseases: a population-based cohort study. Am J Epidemiol 2019;188:1311-8

5 Wu M-C, Huang J-Y, Chen H-H, et al. Effect of early eradication therapy on systemic lupus erythematosus risk in patients with Helicobacter pylori infection: a nationwide population-based cohort study. Lupus 2020;29:751-60. 